\title{
Organizational Innovation in High-Tech Companies in the Ústí Region (Czech Republic)
}

\author{
Michaela Jánská, Petra Olšová \\ Jan Evangelista Purkyně University in Ústí nad Labem, Faculty of Social and Economic Studies \\ Moskevská 54, 40096 Ústí nad Labem, Czech Republic
}

\begin{abstract}
Employee skills are a source of sustainable competitive advantage. Organizational innovation introduced and managed by company management has a strong influence on the development of innovation capacity. This article follows these innovations in the phases of the employee's life cycle - recruitment, onboarding, retention, development, and departures of employees. The aim is to assess the use of innovative organizational tools. This is done by investigating companies in the high-tech sector in the Ústí Region. There were shortcomings in the recruitment process, the use of more traditional employee retention benefits, and insufficient training programs. In connection with the shortcomings, the inadequate size of the monitored companies is considered.
\end{abstract}

Keywords - innovation, organizational innovation, high-tech companies, employee, employee life cycle JEL Classification: $\mathbf{0 3 1 0}$

\section{Introduction}

Innovation is a central part of the economic growth dynamics and for both, the short and long-term extension of the dynamics of growth in the employment [24]. Companies and governments

DOI: 10.18421/TEM92-17

https://doi.org/10.18421/TEM92-17

Corresponding author: Michaela Jánská, Jan Evangelista Purkyně University in Ústí nad Labem, Faculty of Social and Economic Studies Moskevská 54, 400 96 Ústí nad Labem, Czech Republic.

Email: michaela.janska@ujep.cz

Received: 22 October 2019.

Revised: 03 February 2020.

Accepted: 10 February 2020.

Published: 27 May 2020.

(c) BY-NC-ND (C) 2020 Michaela Jánská \& Petra Olšová; published by UIKTEN. This work is licensed under the Creative Commons Attribution-NonCommercial-NoDerivs 3.0 License.

The article is published with Open Access at www.temjournal.com support innovations, because they increase the productivity and the ability to compete. Innovations require time, effort and resources. Particular segments of the economy show different intensity of research and development. It is likely that the segment of high-tech technology has to invest more in the research and development in order to be able to survive and grow on the market [4]. Papers on the innovation activities of firms focus for the most part on the role of corporate characteristics, such as the size, cash flow and diversification [7]. A fewer number of empiric studies consider the characteristics of the management of the human capital, primarily in relation with attribute on the level of a company [19], [1]. [28] agrees with the idea of the human capital as the most important resource for a company. The development of the human capital is researched by [33], who works with the human capital development index and divides it in three sub-indices: a social development of the human capital, a development of innovations in the field of the human capital, and prospects of the human capital development.

Employees' skills are the only real source of a sustainable competition advantage, as compared to the other resources, such as technology, and can be easily targeted by the competition. The innovation capacity of the human capital is described in firms by three factors, i.e. people, knowledge and creativity. Results show that managerial procedures raising the innovation output in employees have a strong impact on the development of the innovation capacity [30].

The goal of the enterprises is to maximize the company value, [17] have proven the interconnection between investments in the human capital and a growth in income and market value. According to [12], company owners do care if an investment in human resources brings financial results.

According to the Czech Statistical Office [9], it is possible to understand organizational innovations as being the "introduction of new organizational methods in corporate procedures, jobs, organizational and outer relations“. Such innovations can be targeted at a growth in the overall output of a company by reducing administrative costs or work 
environment improvement. In terms of the organization of human resources, innovations are changes on the level of management, changes in communication channels, new education and training systems, formation of independent teams, leaving more responsibility on employees, and other methods supporting growth in the human capital efficiency.

When monitoring organizational innovations, we focus on particular phases of the employee life cycle: recruitment, onboarding (the process of an adaptation in a company), employee retention, development of employees, and departures of employees from a company. During the entire cycle, it is necessary for a company to be interested in a feedback from its employees, because they can provide a more detailed view on internal processes and features that can be improved [26]; [10]. The popularity of the use of social networks for the recruitment of employees is growing [21]; [22]. The e-recruitment, a process including social networks and mobile applications, makes the recruitment process shorter [34]. According to the surveys of the authors of [15], an allocation of an employee available to the newcomer for a certain period of time is the most efficient practice in the field of onboarding.

Many organizations are discussing the field of human resources, particularly the way how to properly maintain and create talents and the importance of employees being identified with the corporate culture. [3] claim that they had found serious weaknesses in traditional methods. According to [27], there are many time-tested retention strategies, such as a transparent culture of labour, openness, a pleasant work environment, internal trust, pride and communication. Success depends on the ability to hire new employees and maintain a talented labour force.

Training significantly impacts organizational innovations in innovative manufacturing companies. The higher the level of training is in firms, the higher the level of innovation of products, processes and administrative innovations will be [18]. Positive results have also correlated with administrative innovations, which can be identified with the corporate culture and the organizational structure [18], which have proven to be the most renowned managerial procedures in the study [28]. A mutual relation of the strategic human resources management and the business orientation is confirmed by a study published by [35], which focuses on an important role of the business orientation on the relation between the human resources management and the entire society. The results show that this relation is positively reflected in the financial output of a company and also partially on the output of the employees.
Authors [20] have compared the differences of the development of the capital between small enterprises (up to 50 employees) and larger companies with four basic researched items: those being education, training, the willingness to introduce changes at a workstation, and satisfaction with the work. The research revealed differences between the size of a company and determinants of innovation in a company. In terms of small companies, it has been proven that the innovating human capital can be more advantageous primarily in the field of expert training and the willingness to change. This means that small companies employing managers, participating in training and tending to changes, most likely innovate more.

The phase of the departure of an employee is important for a company. It provides the employers with the information on the internal operation and subjective feelings of former employees related with the operation in the company.

\section{Methodology}

Agglomeration and localization economies positively and significantly affect the rate of innovation in high-tech industries, but their effect on low-tech industries is much less pronounced [2]; [29]. Innovation in Europe is frequently assessed in a context of the level of technology. In Europe, hightech firms are associated with technological innovation. High-technology fields are very often rapidly growing and with good profit margins [11]; [16]. Properly motivated and trained employees, who are well organized in high-tech industries, raise not only the efficiency of a company but also the overall rate of innovations. As shown by studies [14], small and medium-sized enterprises in high-tech industries showed higher efficiency after involving expert employees in strategic management. According to the CZ NACE classification, the high-tech segment, or the group of branches with high technology demands, includes economic activities using advanced technologies. Outputs of such activities are often followed by high costs on innovations and research and development. This segment is thus divided in the high-tech industries and services. A list of activities included in the segment was updated in 2010 to correspond with Eurostat. These are the groups of activities included in the high-tech segment:

- Pharmaceutical industry - Production of pharmaceutical products and preparations;

- Electronic industry - production of computers, electronic and optic devices and equipment;

- Air and space industry - production of aircrafts and their engines, spaceships and related equipment; 
- Audio-visual activities;

- Activities in the field of provision of ICT services;

- Information activities;

- Research and development [8].

An important question was to find out if there were any relationships between tools from particular phases of an employee life cycle and general features of addressed companies, such as the size, segment, kind of activity and the owner's nationality.

Primary data for this paper was attained with the help of an online questionnaire survey targeted at 161 companies, primarily HR managers, active in the high-tech segment in the Ústí Region during October and November 2018. The companies active in the segment were searched with the help of the database Albertina. A non-parametric Kruskal-Wallis test in the Statistica 13 program was used to find correlations between methods in the human resources organization and general parameters of particular companies. The p-value was chosen to show the existence of any correlation. Our zero hypothesis is the statement that there was no dependence between the researched factors. The value for the level $\alpha$ was kept at standard 0.05. In these cases, it was possible to state only the possible existing relation, however, not unconditionally necessary, due to a low number of respondents.

\section{Results and Discussion}

The sample includes 51 companies and all of them, with an exception of two, are owned by domestic businessmen. Due to a low number of foreign owners, it was not possible to determine a correlation between the rate of used methods and this general parameter. More than three quarters of the surveyed enterprises are micro-companies $(1-9$ employees). The share of small enterprises reaches only $17.6 \%$, while there were only three mediumsized enterprises (50 - 249 employees) in the surveyed sample. Because there is a low share of small and medium-sized enterprises in the survey, they will be put together in a joint group in the statistical survey to represent a larger sample and the results to be more credible. Nearly all the companies, with an exception of four, focus on services. According to the CZ-NACE classification, some $68.6 \%$ of the enterprises surveyed are in the field of information technology. A total of eight companies are active in the field of information activities. Each segment of the production of computers and optical devices and telecommunication activities is represented by four companies.

\subsection{Employee Recruitment}

The companies were asked in the survey to what extent they used the tools offered in the system for the recruitment process administration (for instance ads at job boards, the creation of databases of candidates, video-interviews, chatbots, etc.). Only a few companies use such tools. Relatively, the most popular tool is the display of ads at job boards with an average grade of use at the value of 3; the second most popular tool is the display of vacancies on social networks (average value 2.7). The abovementioned values show that the tools are rather not used (the remaining tools show even a weaker position). A very strong correlation ( $\mathrm{p}$-value = 0.0048) was found between the size of a company and the tool of the candidate database creation. In companies larger than the micro ones, there can be found a wider offer of job positions and innovative segments and high-tech industries can easily forecast the establishment of new positions or the need for new knowledge the company currently does not have. As proposed by authors [6], such a database can help a company to keep a good track of current applicants and also former ones, who can be then targeted. When seeing the results shown only by small and medium-sized enterprises, the use of this tool is on an average value of 4, while this value does not show the value of 2 in the total results. Microcompanies in this segment are rather narrowly focused, so it is not necessary for them to create such databases.

A strong correlation ( $\mathrm{p}$-value $=0.0166)$ was seen between the kind of segment and the use of so-called chatbots, a computer program for automated communication with people. This tool is very popular in companies from the information activities and telecommunication activities segment. They often use it for customer support services. A chatbot is able to automatically answer FAQs without requiring the involvement of an actual human. It is only logical and efficient, if such a program is already used in a company, to program it to automatically answer candidates. Authors [6] see the advantage of the chatbots not only in the speed of a reaction of an "employer" to the relevant job applicant, but they also contribute in the better perception of the applicant, and it was agreed also by authors [34], because they provide the applicants with a feeling of communication directly with someone from the company.

The segment of information activities uses a toll for the collection and work with data and graphs, which provide better information and better target applicants. The P-value of 0.0366 shows the relation of the segment with the tool. Authors [34] claim that all information about the candidates is very important in the recruitment process. It is possible to make the recruitment campaigns more efficient, thanks to the 
information. The online environment makes it possible to gather more data to work with. For instance, the knowledge of a device used to view an advertisement (a desktop, a laptop, a smartphone, a tablet) provides information about what formats a company's website or advertisement campaign has to be adjusted to.

\subsection{Employee Onboarding}

The length of the onboarding process is an important part of an employee life cycle. According to [15], it is necessary for an employee to be able to correctly absorb as many pieces of information as possible. It is thus necessary not to hasten the process and gradually inform the employees about more difficult processes and higher volumes of information. The authors monitored positive longterm results and a lower fluctuation in employees, whose onboarding process took at least one month. According to the questionnaire survey, the process takes one month or longer only in $45 \%$ of respondents. A strong correlation occurred among the kind of segment ( $\mathrm{p}$-value $=0.0228$ ), the field of business ( $p$-value $=0.024)$ and the length of the onboarding process. All enterprises dealing with the production of computers, electronic or optical devices and the majority of enterprises from the field of information technology emphasize the onboarding process, which takes more than one month there.

In terms of particular onboarding practices, the most popular is the use of a prepared workstation (the average value of 4.64). Managers thus show their interest in an employee and try to adjust the working environment for them to feel as good as possible [15].

An allocation of a colleague helping and counselling a new employee during the onboarding process (the average value of 4.5 ) is a popular tool among the respondents. Even though the p-value reaches 0.0647 , it is possible to use such a small sample to reject the zero hypothesis and state an existing relation between this method and the segment of information and telecommunication activities. Enterprises involved in the segments show an above-average rate of use of this onboarding practice.

Another rather popular practice includes the corporate tour (the average value of 3.9), a personalized greeting from a manager (the average value of 3.84) and a manager spending time with a new employee (the average value of 3.74).

A structured plan (the average value of 2.19) emerged in the survey as a much neglected tool. The structure plan provides a new employee with a specified schedule of tasks during the onboarding process, so they know about their upcoming tasks and duties. Authors [15] have found out that employees appreciate such a format. Even though the p-value reaches 0.097, the small sample makes it possible to state that there is a correlation in which the size of a company plays a role in the use of this method. Micro-companies use this method more frequently than small and medium-sized companies.

\subsection{Employee Retention}

A non-financial benefit - meal vouchers - has been shown as the most used form to retain employees. The average rate of the use of this benefit on a scale from one to seven was 4.33. The use of this form of benefits directly depends ( $\mathrm{p}$-value $=$ 0.0395 ) on the size of a company.

Non-financial tools to retain employees also include the appreciation and commendation with an average value of 4. Employers should not save appreciation and commendation in deserved situations; however, this should be done to a certain degree, as mentioned by authors [27]. This form of encouragement, the display of the appreciation of an employee and their work, has proven to be a powerful stimulus. Relatively used methods supported also by [31] include target sharing (the average value of 3.27), flexible working hours (the average value of 3.15) and the home office, when possible for the job position (the average value of 3.56). A strong correlation ( $\mathrm{p}$-value $=0.0264$ ) has been shown between the segment of activities in the field of information technology, where the corporate targets sharing is used above average compared with the rest of the segments. Employers or managers, sharing corporate targets with their employees and asking about their opinion, show respect to their employees' opinion and provide them with a possibility to contribute in the operation of the company.

Less used non-financial tools for the motivation and retention of employees further may include the provision of more days for holidays, corporate events and teambuilding, which are more typical for larger companies. Last but not least, a tool to retain employees is the possibility of career growth. A positive relation between the size of a company and this tool has been confirmed. The use of this tool in larger companies has a value of 4.25.

\subsection{Development of Employees}

It is also necessary to have correctly trained management, i.e. managers and HR managers, to achieve the most efficient results in the training of employees. While the addressed companies provide a rate of the provision of training for managers with an average value of 3.6, this figure reaches 1.9 in terms of HR managers, i.e. almost never or on rare occasions. Even though the p-value reaches the value 
of 0.0635 , it is possible, under the current conditions, to state a relationship between this kind of segment and the rate of training provided to managers. The highest rate of the provision of training to managers was observed for segments of telecommunication and information activities.

Authors [35] have proven that correctly and gradually trained managers are able to innovate the organization of the entire HR process, which positively impacts both employees and the financial part of the company. After a comparison, they found a conclusion that a good organization and following innovations occurred after HR management training caused a growth in the labour productivity by nearly $19 \%$ and a turnover generated by small enterprises grew nearly $10 \%$ a year.

The enterprises feel a deficiency in the field of sales skills, such as communication and sales presentation. The average value on the Likert scale was 4, when 1 represented no deficiency and 7 high deficiency. More than one third of the respondents quantify this deficiency by the value of 5 and higher. Sales skills secure a growth for companies in financial terms. According to authors [20], the art to sell is an essential condition for a growth of the entire company in the growing and innovating market. It helps the companies to avoid their decline in a hypercompetitive environment. According to authors [35], small enterprises improving managerial skills, such as sales skills, show an annual growth in their turnover by nearly one fifth.

The enterprises think their expert knowledge, necessary in the high-tech segment, was their strongest point. A slight fluctuation was monitored for companies experiencing a lack of expert labour force, which is common in the Ústí Region. The respondents also revealed weaknesses in managerial skills, such as the leadership, motivation or delegation, where more than one half mentioned values of 4 and higher. When considering the composition of the sample, this relationship is shown primarily in micro-companies. Supposing that the owner was also the executive director or manager of the entire company, who, without no doubt, possessed enough expert knowledge, they, in a view of HR managers, lacked some managerial skills.

Rather, the respondents do not organize the development of their employees with the help of training and optional training for employees are not offered by more than one half of them. Those offering training show the average rate of the use by employees at only 3.7. The interest in training shown by employees is however higher than the rate of the actual use in the companies. This means that the employers provide training, which is not interesting for their employees or it lacks quality.
Employees are most often trained internally or in combination with an external agency. The form of internal training is a cost-acceptable version of training primarily for small enterprises. In microcompanies and small companies, the form of internal training could be both an advantage and a disadvantage due to the fact that the majority of colleagues know each other, which, according to [32], could be both a key to success and a sticking point (the employees do not have to take the training program seriously).

The assessment of the rate of used tools for training follows. A correlating relationship has been proven ( $p$-value $=0.0017$ ) in the field of information and communication activities when using a practical demonstration of situations. Because these segments deal, for instance, with the procession of data, hosting and web portals (information activities) or activities related with wireless and fixed communication networks (telecommunication activities), employees are trained to be able to correctly behave and proceed in particular situations. The rate of the use of this tool in such enterprises nearly reached the value of five. This value was only on the level of three in the total average.

The kind of segment influences also the use of a cross training (a view in colleagues' work). A strong relation ( $\mathrm{p}$-value $=0.0031$ ) was found in companies manufacturing computers, electronic and optic devices. It is necessary to know what kind of work colleagues are doing in the manufacture of such devices, because the work of a particular employee depends on other people's work when assembling a single device.

In terms of an interaction with an instructor, an average rate (the value of four) was exceeded by tools of a discussion with the instructor, including open-end questions and storytelling (explanation of instructor's experience). [5] thinks a maximal interaction with an instructor was an indispensable part of training. During storytelling, employees are able to picture a particular situation, conditions under which the situation happened and how the instructor dealt with the problem. This kind of activity develops ways of thinking and creativity, necessary in nonstandard situations. The importance of the abovementioned development tools has been agreed on by [25] and also [5].

Mentoring depends primarily on the size of a company (p-value $=0.0477$ ), it is frequently used by small and medium-sized enterprises. Mentoring could be one of the least expensive versions of internal training, where the managers themselves or an experienced employee teach some new features or changes in current processes. Mentoring requires enough time and an appropriate approach and not everyone is able to meet the requirements. The 
employee training result can thus be negatively impacted as employees could incorrectly learn how to solve issues or procedures.

The possibility to win a certificate with the help of an online lesson is an option very rarely used by the respondents, however, there is a correlation between the use of this tool and the size of a company $(\mathrm{p}$-value $=0.022)$. Other only minimally used or nearly unused tools include repeated training, apprenticeship, web trainings or the use of quizzes and tests to check out if employees understand everything correctly.

A corporate email was mentioned in the survey as a training method. The average rate of use by the respondents was high (4.53). Author [5], however, thinks the form of "training" was absurd. A sent email or a document attached to an email cannot be considered an adequate training method. This often causes misunderstandings, incomprehension and completely inefficient training. It is necessary to personally meet someone who understands a given problem and is able to explain it. Employees also assign more importance and attention to a personal meeting.

\subsection{Departure of Employees}

Information from employees leaving a company is important for improving the internal operation [23]. According to survey results, the use of final interviews was below average (3.7). Even though the $\mathrm{p}$-value in the relation of final interviews and the kind of segment reached 0.168 , it is possible to state, when reflecting the majority representation of enterprises from the segment of information technology, that there could be a correlation between the two factors. The use of the final interview was mostly monitored in enterprises from the segment of information technology. Final interviews can bring useful information, but according to [13], employees leaving a company have to be honest. The authors, however, have not recorded honesty, as the answers of employees were insincere and skewed in the majority of cases, when such interviews were monitored and put under inspection in the companies.

A leaving questionnaire can be used as a version of the final interview. Employees can thus explain themselves in a simpler, and in bigger companies, also anonymous form. The questionnaires are suitable for larger enterprises to keep a wider spectrum of feedback. It is also possible to monitor changes with the help of a thorough analysis. The respondents only rarely use such questionnaires.

A departure, or the final interview, should be followed by an offer for a new job. This manifestation of good will makes an employee feel that the company appreciated their work and it would be hard to find a replacement. The results show that this option is not offered.

\section{Conclusion}

The recruitment process in the company shows insufficiencies and the companies are not able to find suitable candidates for the offered job positions. They significantly underestimate the e-recruitment, even though they use its tools (primarily job portals and social networks). Due to the high representation of micro-companies in the survey, the low rate of use cannot be attributed to the lack of knowledge, but rather to the unnecessity of the use for such companies. In terms of small and medium-sized enterprises, the frequency of the use of such tools was higher, however, primarily the use of online platforms was below expectation.

The length of the onboarding process influences the fluctuation of employees. The employees use their first weeks to decide on staying or leaving a company. The results show that nearly one half of respondents allocate at least one month, an optimal period of time, for this process.

It is most popular among companies to use meal vouchers as benefits to maintain employees. The offer of the meal vouchers depends on the size of a company and larger companies show a higher rate of the meal voucher use. Non-financial motivation tools include appreciation and commendation and a lower share of companies provide their employees with more flexible working hours or a home office.

The development of employees in the form of training is currently perceived as a benefit. Results, however, show that the rate of the use of nonmandatory training offered by firms is very low. Employees demand training, however, the final participation in the training is minimal. It is possible to conclude that even though the employers offer training to their employees, the employees are not interested in them or doubt their quality. Training develops employees and can lead to innovative ideas and then innovations. It is necessary to have welltrained management to be able to propose suitable training programs. The rate of the provision of training to HR managers, who are responsible for the HR organization process, has proven to be insufficient.

The companies feel deficiency in their sales and managerial skills. It is necessary to remove such deficiencies, for instance by changing training lessons, to improve sales and correctly manage and motivate employees. These companies use the most internal trainings, eventually in combination with an external agency.

The companies feel strong in the field of the expert knowledge, an inseparable part of the operation in the high-tech segment. Enterprises in the field of 
information activities and communication activities very frequently use practical demonstrations during training. This makes it possible for them to better prepare their employees for different situations. It would be good to introduce this tool, at least to some extent, in all enterprises. The cross-training tool is then used primarily by companies involved in the manufacture of computers, electronic and optical devices.

The departure of an employee should be followed by an exit interview to provide a formal farewell to the employee and gather valuable information, which can be used to improve the internal environment of the company. Exit interviews are used rather by firms focused on telecommunication and information activities. The method is limited by a possible insincerity and consequent provision of false information by the employees.

The survey showed that companies from the field of information activities and telecommunication activities were the most active ones in the use of all monitored tools among the surveyed enterprises focused on high-tech segments. Even though the rate of the use of their methods in the entire employee life cycle, from the recruitment up to the departure, could be higher to achieve better results among employees and the ability to compete, they are still ahead of their competitors from other segments in terms of the HR capital organization. Many renowned tools to stimulate and maintain employees are either not used or used only rarely. It could be caused by the fact that there is a lack of desired education for employees involved in the HR management, so they rather stick to traditional tools and do not know about the new ones, do not trust them, or have limited rights to introduce organizational innovations.

Investments in the organizational process quality improvement could be a stimulus for innovation thinking and employees' activities.

\section{Reference}

[1]. Arvanitis, S., \& Stucki, T. (2012). What determines the innovation capability of firm founders?. Industrial and Corporate Change, 21(4), 1049-1084.

[2]. Audretsch, B. (1998). Agglomeration and the location of innovative activity. Oxford review of economic policy, 14(2), 18-29.

[3]. Cable, D. M., Gino, F., \& Staats, B. R. (2013). Reinventing employee onboarding. MIT Sloan Management Review, 54(3), 23.

[4]. Catalini, C., \& Gans, J. S. (2016). Some simple economics of the blockchain (No. w22952). National Bureau of Economic Research.

[5]. Cekada, T. L. (2012). Training a multigenerational workforce: Understanding key needs \& learning styles. Professional Safety, 57(03), 40-44.
[6]. Chhabra, A., \& Ahuja, V. (2018). Recruitment Trends in the Contemporary Era. In Multidisciplinary Perspectives on Human Capital and Information Technology Professionals (pp. 24-37). IGI Global.

[7]. Cohen, W. M. (2010). Fifty years of empirical studies of innovative activity and performance. In Handbook of the Economics of Innovation (Vol. 1, pp. 129-213). North-Holland.

[8]. CZSO (2016): High-tech sektor. Retrieved from: https://www.czso.cz/csu/czso/high tech sektor [12. September 2019].

[9]. CZSO (2018): Inovační aktivity podniků - 2014 2016. Retrieved from:

https://www.czso.cz/csu/czso/inovacni-aktivitypodniku-2014-2016 [12. September 2019].

[10]. Fjell, S. (2017): The 7 Stages of the Employee Lifecycle and Why They Matter. Retrieved from: https://www.questback.com/blog/the-7-stages-of-theemployee-lifecycle-and-why-they-matter/ [15. October 2019].

[11]. Hollanders, H., Es-Sadki, N., Vértesy, D., \& Damioli, G. (2017). European Innovation Scoreboard 2017-Methodology Report. European Commission.

[12]. Jiang, K., Lepak, D. P., Hu, J., \& Baer, J. C. (2012). How does human resource management influence organizational outcomes? A meta-analytic investigation of mediating mechanisms. Academy of management Journal, 55(6), 1264-1294.

[13]. Johns, R. E., \& Gorrick, J. (2016). Exploring the behavioural options of exit and voice in the exit interview process. International Journal of Employment Studies.

[14]. Karami, A., Jones, B. M., \& Kakabadse, N. (2008). Does strategic human resource management matter in high-tech sector? Some learning points for SME managers. Corporate Governance: The international journal of business in society, 8(1), 7-17.

[15]. Klein, H. J., Polin, B., \& Leigh Sutton, K. (2015). Specific onboarding practices for the socialization of new employees. International Journal of Selection and Assessment, 23(3), 263-283.

[16]. Kurik, S. (2002). Innovation in Estonian enterprises 1998-2000. Ministry of Economics.

[17]. Latyshev, I. O., \& Akhmetshin, E. M. (2015). Methodological approaches to analyzing the indicators of human capital management in the interests of innovation development of enterprise. International Business Management, 9(6), 1565-1570.

[18]. Ling, T. C., \& Nasurdin, A. M. (2010). Human resource management practices and organizational innovation: An empirical study in Malaysia. Journal of Applied Business Research (JABR), 26(4).

[19]. Lynskey, M. J. (2004). Determinants of innovative activity in Japanese technology-based start-up firms. International Small Business Journal, 22(2), 159-196.

[20]. McGuirk, H., Lenihan, H., \& Hart, M. (2015). Measuring the impact of innovative human capital on small firms' propensity to innovate. Research Policy, 44(4), 965-976. 
[21]. Nagendra, A. (2014). Paradigm shift in HR practices on employee life cycle due to influence of social media. Procedia Economics and Finance, 11, 197207.

[22]. Nikolaou, I. (2014). Social networking web sites in job search and employee recruitment. International Journal of Selection and Assessment, 22(2), 179-189.

[23]. Norton, G. (2014). Onboarding not working. Learn from your offboarding practices. Workforces Solutions Review, 11, 13.

[24]. Okumu, I. M., Bbaale, E., \& Guloba, M. M. (2019). Innovation and employment growth: evidence from manufacturing firms in Africa. Journal of Innovation and Entrepreneurship, 8(1), 7.

[25]. Onyango, J. W., \& Wanyoike, D. M. (2014). Effects of training on employee performance: a survey of health workers in Siaya County, Kenya. European Journal of Material Sciences, 1(1), 11-15.

[26]. Rouse, M. (2018): Employee life cycle. Retrieved from:

https://searchhrsoftware.techtarget.com/definition/em ployee-life-cycle [17. October 2019].

[27]. Sandhya, K., \& Kumar, D. P. (2011). Employee retention by motivation. Indian Journal of science and technology, 4(12), 1778-1782.

[28]. Shafeek, H. (2016). The impact of human recourses management practises in SMES. Annals of the Faculty of Engineering Hunedoara-International Journal of Engineering, 14(4).
[29]. Shefer, D., \& Frenkel, A. (1998). Local milieu and innovations: Some empirical results. The Annals of Regional Science, 32(1), 185-200.

[30]. Smith, A., Courvisanos, J., Tuck, J., \& McEachern, S. (2012). Building the Capacity to Innovate: The Role of Human Capital. Research Report. National Centre for Vocational Education Research Ltd. PO Box 8288, Stational Arcade, Adelaide, SA 5000, Australia.

[31]. Thompson, N. W. (2011): Managing the Millennials: Employee Retention Strategies for Generation $Y$. Senior Thesis. Claremont McKenna College.

[32]. Troy, D. (2017): Internal Vs. External Training: Which Is Right For You? Retrieved from: https://elearningindustry.com/internal-vsexternal-training-right [17. October 2019].

[33]. Vaitkevičius, S., Čiutienè, R., Meilienè, E., \& Savanevičienè, A. (2015). Typology of human capital development in EU countries. Procedia economics and finance, 23, 1641-1648.

[34]. Zaheera, A., Khan, N., \& Senthilkumar, C. B. (2015). E-recruitment: Criteria for its effectiveness and modern trends. International Journal of Business Administration \& Management Research, 1(3).

[35]. Zehir, C., Gurol, Y., Karaboga, T., \& Kole, M. (2016). Strategic human resource management and firm performance: The mediating role of entrepreneurial orientation. Procedia-Social and Behavioral Sciences, 235, 372-381. 